\title{
Scale invariance in the retrieval of retrospective and prospective memories
}

\author{
ELIZABETH A. MAYLOR, NICK CHATER, and GORDON D. A. BROWN \\ University of Warwick, Coventry, England
}

\begin{abstract}
How does memory retrieval depend on time scale? One strong hypothesis is that such retrieval is scale-invariant (i.e., invariant across different time scales). To test this hypothesis, three groups of participants were given 4 min to recall what they did yesterday, last week, or last year (retrospectivememories), and $4 \mathrm{~min}$ to recall what they intended to do tomorrow, next week, or next year (prospective memories). In line with scale invariance, retrieval performance was indistinguishable across time scales, for both retrospective and prospective memory. An additional finding was that significantly more prospective memories were recalled than retrospective memories, confirming previous observations of the "intention-superiority effect" (Goschke \& Kuhl, 1993).
\end{abstract}

A striking discovery in the natural and social sciences has been that a wide class of time-varying signals has an invariant statistical structure over a large range of time scales. Examples of such scale-invariant time-varying phenomena arise commonly in cases as various as river discharge rate (Mandelbrot \& Wallis, 1969), noise in electrical circuits, amplitude variation in music and speech (Voss, 1978; Voss \& Clark, 1975), fluctuationsin economic time series concerning commodity and stock prices (Mandelbrot, 1997), and ecological time series concerning population numbers (Bak, 1997). Such scale invariance is so ubiquitous that it has been suggested that it may be an automatic consequence of states of "self-organized criticality" characteristic of highly complex natural dynamical systems (e.g., Bak, 1997).

If a phenomenon is scale invariant, it should be impossible to determine the scale at which the phenomenon is being represented. Many phenomena in nature, including those mentioned above, are scale invariant in a statistical sense-that is, the statistical properties of the phenomena are replicated at each scale. This means that no statistical analysis can allow us to identify the scale of the phenomenon in question. For example, in Figure 1, a scale-invariant time-varying input is illustrated at two levels of resolution. The resulting patterns have identical statistical properties.

Scale invariance in temporal variation seems a natural default assumption concerning time-varying inputs to the cognitive system. Anderson and colleagues have argued

This research was supported by grants from the Medical Research Council of Great Britain (G9608199 and G9606610N). We are grateful to Carolyn Moss for collecting the data, to Janet Vousden for helpful discussion, and to Geoffrey Loftus, David Rubin, and an anonymous reviewer for useful comments on an earlier version of the article. Correspondence concerning this article should be addressed to E. A. Maylor, Department of Psychology, University of Warwick, Coventry CV4 7AL, England (e-mail: elizabeth.maylor@warwick.ac.uk). that memory retrieval may be an adaptive reflection of the structure of the environment (Anderson \& Milson, 1989; Anderson \& Schooler, 1991). This leads immediately to the hypothesis that scale-invariant properties of the environment may be reflected in scale-invariant aspects of memory retrieval (see Brown, Neath, \& Chater, 2000 , for detailed discussion). There are several lines of evidence consistent with this hypothesis. First, scaleinvariant memory retrieval implies that forgetting curves should have the same shape over a range of time scales. This is evident in the fact that the best-fitting power functions for forgetting over a wide range of time scales have similar exponents, for example, over time scales of $40 \mathrm{sec}$ to 2 weeks (Wixted \& Ebbesen, 1991) to 50 years (Bahrick, 1984). Second, the ability to retrieve an item appears to be a ratio of the interitem interval and the time between item presentation and test; this implies that retrieval is invariant over absolute time scale (e.g., Bjork \& Whitten, 1974; Crowder, 1976; but see also Cowan, Saults, \& Nugent, 1997; Nairne, Neath, Serra, \& Byun, 1997). Third, serial position curves have an invariant, or almost invariant, shape over considerable variation in item presentation rate (McCrary \& Hunter, 1953). Thus, scale invariance has the potential to capture a broad generalization about human memory retrieval (Brown, Neath, \& Chater, 2000 ), in the same way that scale invariance has been shown to capture broad generalizations in perception and motor control (Chater \& Brown, 1999).

The aim of the present study was to test scale-invariant memory retrieval directly, and moreover, to test whether scale invariance applies in prospective memory (remembering to do something in the future), as well as in retrospective memory (remembering something from the past). This also allows the present study to address the nature of the relationship between prospective and retrospective memory (see Brandimonte, Einstein, \& McDaniel, 1996, for reviews), and in particular to test for the intriguing "intention-superiority effect" (Goschke \& 


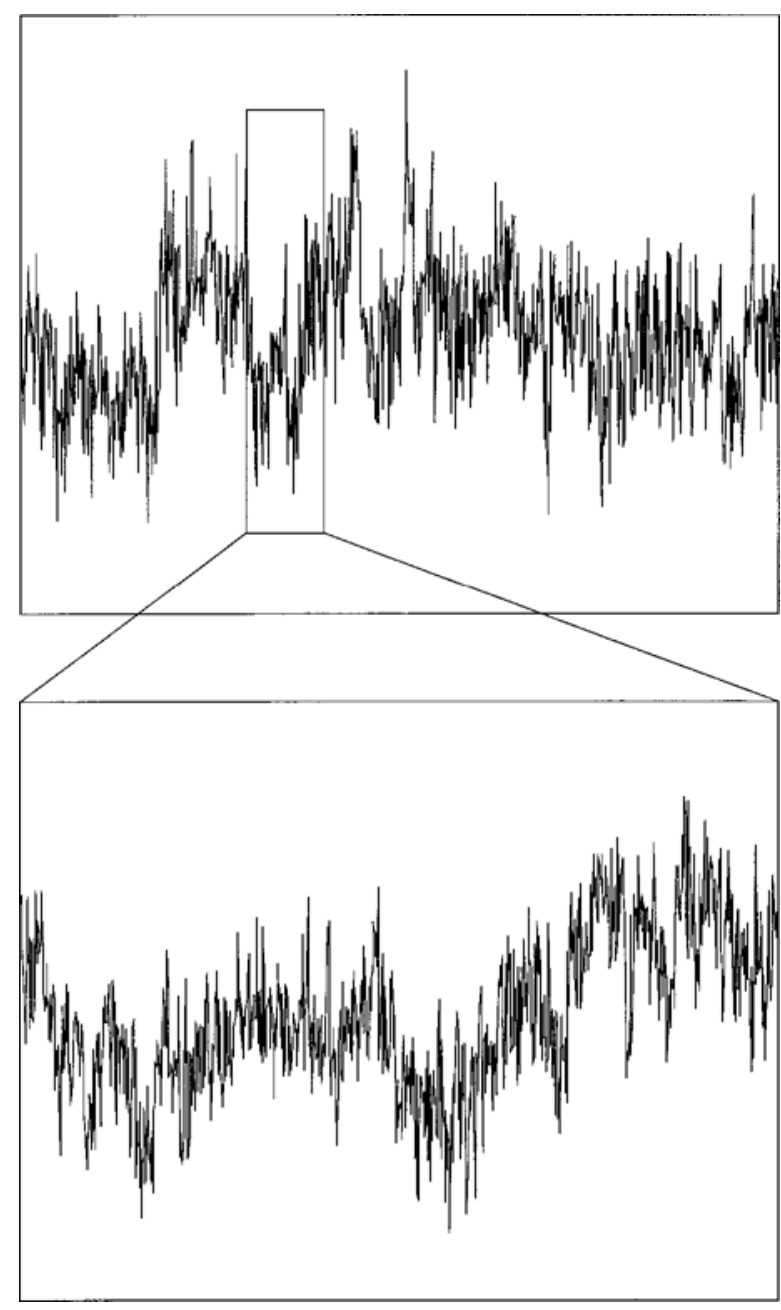

Figure 1. Scale-invariant time-varying input (pink noise). The selected window in the upper plot has been expanded as indicated to produce the lower plot. Note that the structure at each scale is the same, so that it is impossible to determine which plot represents the larger, and which represents the smaller, scale.

Kuhl, 1993, 1996)—namely, that intended activities are recalled better than completed activities.

To assess scale invariance in retrospective and prospective memory, we used a written fluency task in which participants were required to retrieve as many memories as possible in $4 \mathrm{~min}$. In order to examine whether rates of production differed across conditions, the task was divided into eight periods of $30 \mathrm{sec}$. The influence of writing speed was minimized by asking participants to summarize each memory in a single word. Three different groups of participants recalled what they did yesterday, last week, or last year, and what they intended to do tomorrow, next week, or next year. Thus, each participant performed speeded autobiographical memory retrieval from both the past (retrospective memory) and the future (prospective memory), at one of three different time scales (over a day, a week, or a year). Scale invariance predicts that the rate of production should be invariant across these different time scales. Thus, if one were to look at an unlabeled plot of the data, it should not be possible to determine whether the data were obtained from the day, week, or year conditions.

\section{METHOD}

\section{Participants}

Sixty undergraduate students at the University of Warwick were randomly assigned to one of three experimental conditions (day, week, or year); $n=20$ per condition.

\section{Apparatus}

There were two identical response sheets, each of which was divided into eight numbered sections. A stopwatch was used to time the experiment.

\section{Design and Procedure}

Participants were tested individually. They were informed that the experiment was a memory test and that they would be given a category from which they would be asked to write down as many items as possible. They were told that when instructed, they should begin writing in the first section of the response sheet but that after $30 \mathrm{sec}$ they would be told to stop and move on to the next section. It was made clear that this meant they were to finish the word they were writing, move on to the next section, and then continue to write down items from the same category. The participants were told that this procedure would continue until they had completed all eight sections of the response sheet (i.e., after $4 \mathrm{~min}$ ). They would then be required to repeat the task but with a different category.

When the participants indicated that they had understood these instructions, they were given the first category. Without further delay, the experimenter gave the instruction to begin the task. After they had completed the first task, there was a short break before the procedure was repeated with the second category.

The two categories were retrospective and prospective memories. Half of the participants in each of the three conditions performed the tasks in the order retrospective-prospective, and half performed the tasks in the reverse order. The three experimental conditions differed in terms of the time from which memories were to be retrieved (a day, a week, and a year). The retrospective memory category was described as follows: "The category is jobs, appointments, and things you have done yesterday/in the last week/in the last year. Please try to summarize each item with one word. For example, if you went to see the film Titanic, then write down Titanic." Similarly, the prospective memory category was described as follows: "The category is jobs, appointments, and things you intend to do tomorrow / in the next week/in the next year. Please try to summarize each item with one word. For example, if you intend to see the film Titanic, then write down Titanic."

\section{RESULTS}

The numbers of memories produced in each 30 -sec period are shown in Figures $2 \mathrm{a}$ (retrospective memories) and $2 \mathrm{~b}$ (prospective memories). It can be seen that the data were highly similar across the three time scales of a day, a week, and a year. Fewer retrospective memories were produced than prospective memories (mean totals of 19.6 and 20.4, respectively, for a day; 18.8 and 21.0, respectively, for a week; 18.4 and 19.8, respectively, for a year). 
(a) Retrospective Memory

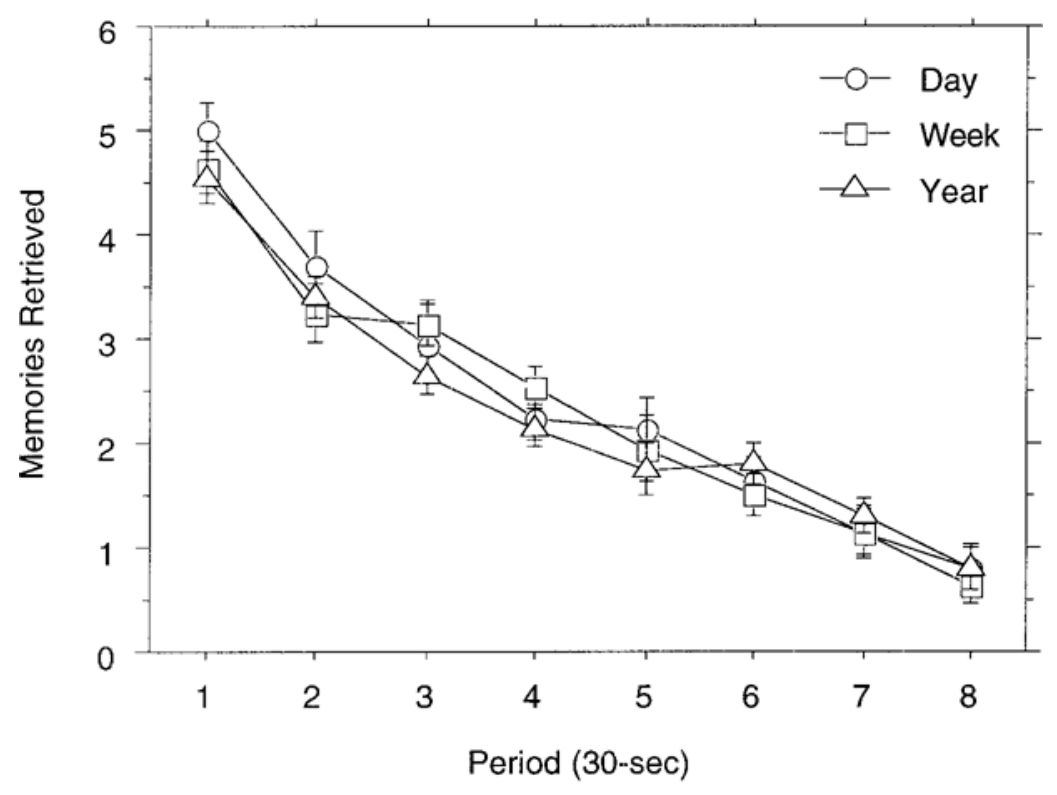

(b) Prospective Memory

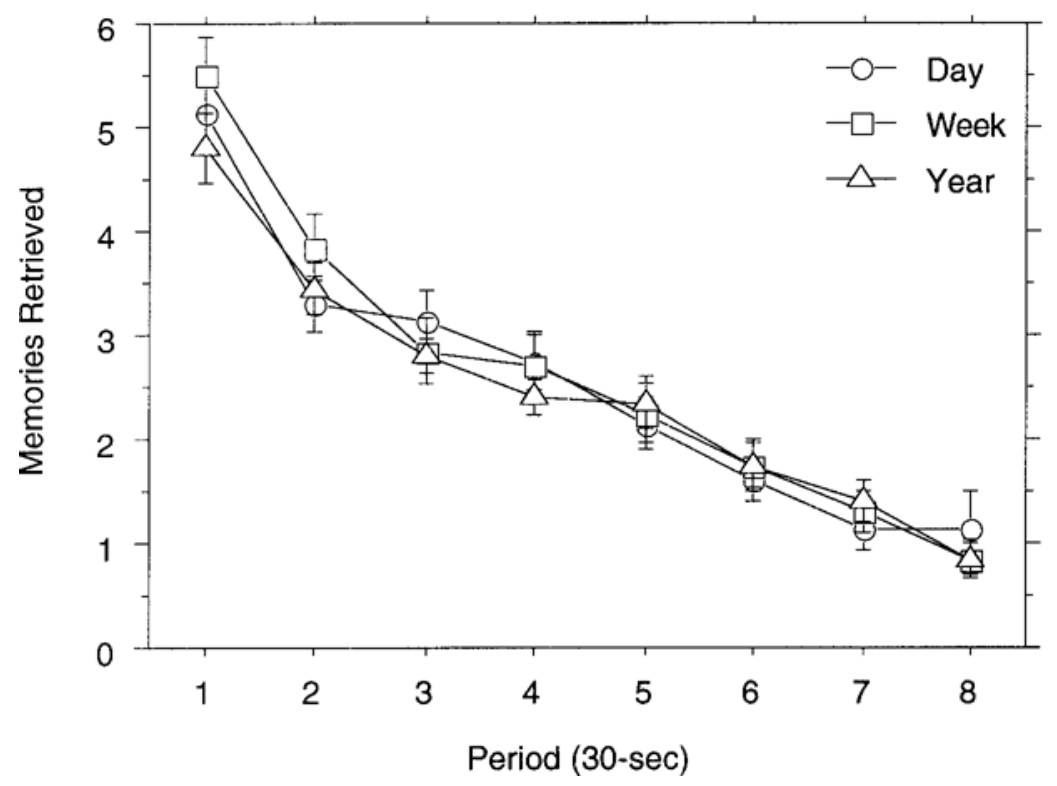

Figure 2. Mean numbers of memories produced in each 30-sec period for (a) retrospective memories, and (b) prospective memories, for three experimental conditions (day, week, and year). Error bars represent $\pm 1 S E$.

Memory production decreased over the 4 min from an overall mean of 4.9 items in the first 30 -sec period to 0.9 items in the last 30 -sec period.

These impressions were consistent with the results of an ANOVA with time scale (day, week, or year) as a between-subjects variable, and task (retrospective vs. prospective), and time period (eight levels, corresponding to the eight 30 -sec periods) as within-subjects variables. There was no overall effect of time scale $(F<1)$, but there were significant effects of retrospective vs. prospective task $[F(1,57)=5.89, p<.02]$, and period $[F(7,399)=$ $218.99, p<.001]$. There were no two- or three-way interactions (all remaining $F$ ratios $<1.13$ ). Note that power to detect an effect of time scale was reasonably high given the relatively small error bars shown in Figure 2.

To examine whether the scale invariance observed in Figure 2 merely arises from the nature of the speeded written fluency task, we compared the present data with 
those from another written fluency task with an identical procedure in which 96 undergraduate students were asked to produce as many words beginning with the letter $s$ as possible (excluding proper names and plurals). Significantly more items were produced in each 30 -sec period in the letter fluency task than in the present memory fluency task, with means of 8.9 items in the first 30 - sec period and 4.3 items in the last 30 -sec period for letter fluency (both $S E \mathrm{~S}=0.2$ ). To compare the rates of production across the two tasks, the cumulative proportion of the total number of items retrieved by each participant was calculated for each $30-\mathrm{sec}$ period. The means are shown in Figures $3 \mathrm{a}$ (retrospective memories) and $3 \mathrm{~b}$ (prospective memories). All functions were negatively

(a) Retrospective Memory

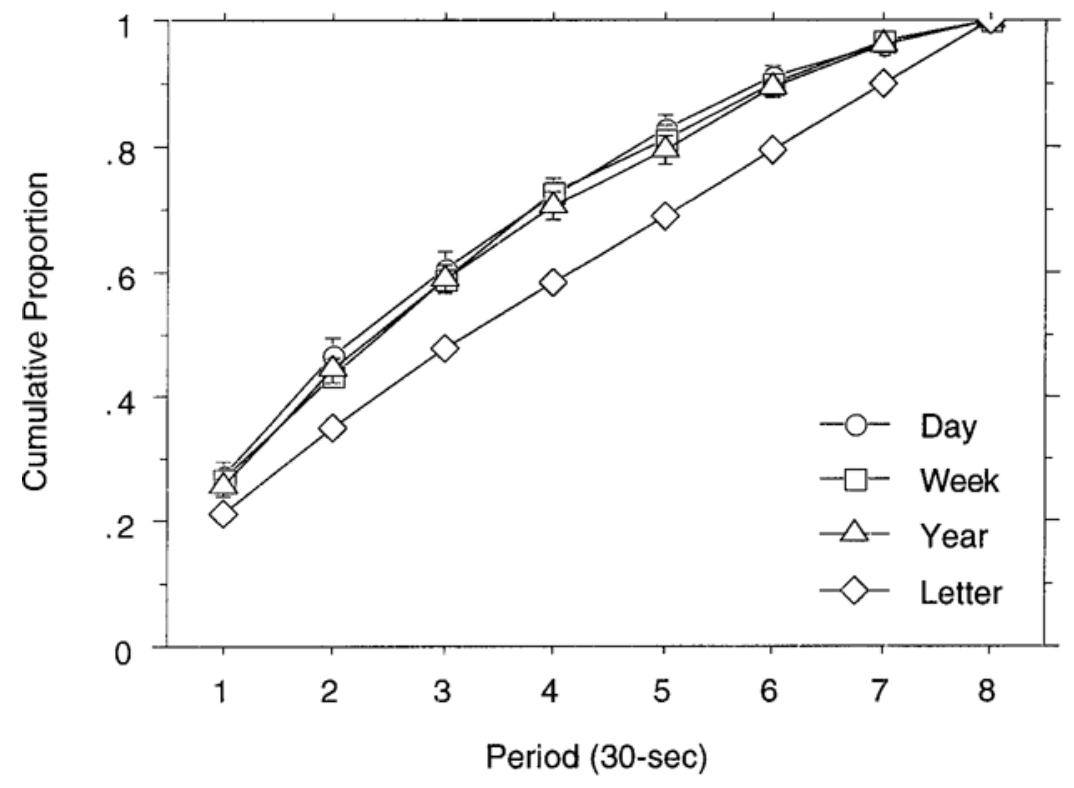

(b) Prospective Memory

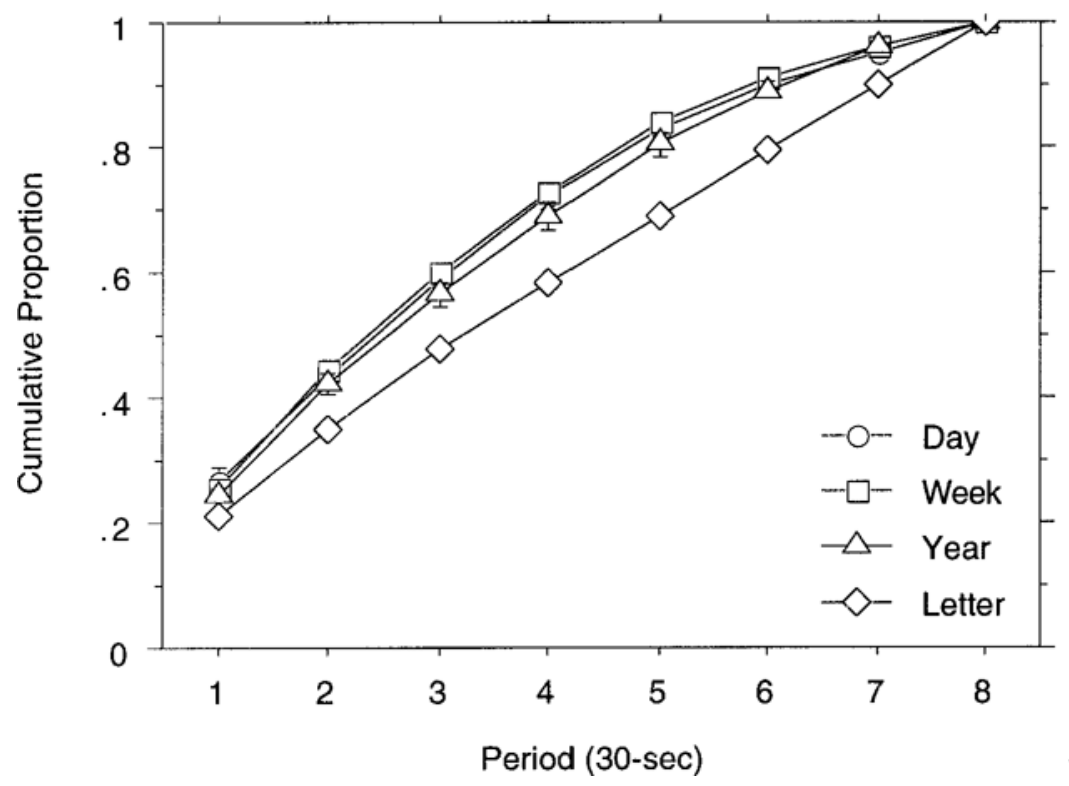

Figure 3. Mean cumulative proportions of total items produced for each 30-sec period for (a) retrospective memories, and (b) prospective memories, for three experimental conditions (day, week, and year). Letter fluency data (words beginning with the letter $s)$ are included for comparison. Error bars $( \pm 1 S E)$ are not always visible, because they are smaller than the symbols. 
accelerated, consistent with random sampling with replacement from a finite search set (see Wixted \& Rohrer, 1994 , for a review of the dynamics of free recall). However, there was a slower rate of approach to asymptote for letter fluency than for the present task, indicative of a larger search set in the former than in the latter case (see Wixted \& Rohrer, 1994, for evidence that the rate of approach to asymptote is inversely related to set size). Importantly, the cumulative output functions for the present task were similar across the different time scales, suggesting that the sizes of the search sets were also similar.

\section{DISCUSSION}

These data are strikingly consistent with scale invariance in memory retrieval (cf. Brown, Neath, \& Chater, 2000). Thus, the functions obtained from retrieval over a day, a week, and a year appear indistinguishable. It seems that memory retrieval is operating in the same way, across different time scales, in both retrospective and prospective memory.

This result may seem puzzling. Surely participants should have been able to provide more information about, for example, the last year rather than the last day, because all information in the latter is included in the former. Pragmatic factors are presumably in operation here-it seems inappropriate to mention eating breakfast this morning when asked to report events of the past year. Relatedly, participants may have reported specific events (e.g., "biology" for a biology lecture) for short time intervals, but generic events (e.g., "lectures") for long time intervals. No doubt different functions from those we have shown could be obtained if participants were explicitly cued to shift to shorter time periods when they ran out of memories at the longer time period. But notice that this does not imply that scale invariance will be violated, because this strategy can itself be applied at each time scale-so people could, in principle, report the last minute, or even the last few seconds. What is remarkable about the present results is that the "natural" level of reporting of widely varying time scales leads to the same level of memory retrieval. This would seem surprising unless there was some underlying scaleinvariant principle at work.

The question arises as to whether scale-invariant retrieval applies in other contexts. We have recently extended our demonstration of scale invariance to memory retrieval at different spatial scales. Using the same procedure, participants were asked to write down "Towns/ cities anywhere in the world" $(n=24)$ and "Towns/cities in Britain" $(n=24)$. Retrieval rates were very similar across the two conditions in each 30 -sec period, with mean total numbers of places retrieved in 4 min of 25.9 and 26.2 for the world and Britain, respectively. Herrmann and Murray (1979) asked participants to generate items from higher level categories (e.g., food, musical instruments) and nested lower level categories (e.g., vegetables, string instruments). In contrast to the present findings, participants recalled significantly more items from the higher level categories $(M=18.4$ items in $3 \mathrm{~min})$ than from the lower level categories $(M=14.2)$. A crucial difference between these cases is that Herrmann and Murray's materials were not necessarily scale invariant. Thus, for nested categories such as foods and vegetables, or musical instruments and string instruments, the lower level category contains a limited number of items that are difficult to subdivide further. However, for autobiographical memory, it is possible to recall one's experiences at ever increasing levels of detail—and the shorter the time interval over which recall occurs, the less significant an item has to be in order to be recalled. And for geographical locations, it is possible (up to a point) to report ever smaller places.

These results are congruent with models of memory that predict similar patterns of performance over different time scales, such as the temporal distinctiveness model of Glenberg and Swanson (1986). In the Glenberg and Swanson model, temporally defined memory search sets become larger as retention interval increases, but the probability of recalling any particular item in the search set decreases as the size of the set increases. Although several models of memory assume that similar processes may govern retrieval over many different time scales (see, e.g., Baddeley, 1976; Bjork \& Whitten, 1974; Brown, Preece, \& Hulme, 2000; Estes, 1972; Glenberg, Bradley, Kraus, \& Renzaglia, 1983; Nairne, 1991), such models do not generally specify the dynamics of retrieval in sufficient detail to enable clear quantitative prediction of the present pattern of results.

Finally, the present study provides a demonstration of a long-term intention-superiority effect for participants' own intentions, consistent with a range of past studies (Goschke \& Kuhl, 1993, 1996; Marsh, Hicks, \& Bink, 1998; Marsh, Hicks, \& Bryan, 1999). But it extends this work by addressing two limitations of previous studies as identified by Marsh et al. (1998). First, existing studies have been confined to the remembering of intentions over short time intervals of just a few minutes. Second, existing studies have been concerned with intentions provided by an experimenter and learned to the same criterion as comparison material. In contrast, participantestablished intentions are almost certainly represented in memory in considerably less detail than are completed tasks. Compare, for example, the stored representations associated with the retrospective memory of having seen a film with the prospective memory of intending to see a film. Moreover, we do not plan everything we do a year, a week, or even a day in advance; thus there are potentially many more memories available from the past than from the future. In view of these considerations, the intentionsuperiority effect observed in the present study seems particularly compelling.

\section{REFERENCES}

Anderson, J. R., \& Milson, R. (1989). Human memory: An adaptive perspective. Psychological Review, 96, 703-719.

Anderson, J. R, \& Schooler, L. J. (1991). Reflections of the environment in memory. Psychological Science, 2, 396-408. 
BADDEley, A. D. (1976). The psychology of memory. New York: Basic Books.

BAHRICK, H. P. (1984). Semantic memory content in permastore: Fifty years of memory for Spanish learned in school. Journal of Experimental Psychology: General, 113, 1-29.

BAK, P. (1997). How nature works: The science of self-organized criticality. Oxford: Oxford University Press.

Bjork, R. A., \& Whitten, W. B. (1974). Recency-sensitive retrieval processes in long-term free recall. Cognitive Psychology, 6, 173-189.

Brandimonte, M., Einstein, G. O., \& McDaniel, M. A. (Eds.) (1996). Prospective memory: Theory and applications. Mahwah, NJ: Erlbaum.

Brown, G. D. A., Neath, I., \& Chater, N. (2000). Simple: A local distinctiveness model of scale-invariant memory and perceptual identification. Manuscript submitted for publication.

Brown, G. D. A., Preece, T., \& Hulme, C. (2000). Oscillator-based memory for serial order. Psychological Review, 107, 127-181.

Chater, N., \& Brown, G. D. A. (1999). Scale-invariance as a unifying psychological principle. Cognition, 69, B17-B24.

Cowan, N., Saults, J. S., \& NugEnt, L. D. (1997). The role of absolute and relative amounts of time in forgetting within immediate memory: The case of tone-pitch comparisons. Psychological Science, $\mathbf{4}$, 393-397.

Crowder, R. G. (1976). Principles of learning and memory. Hillsdale, NJ: Erlbaum.

Estes, W. K. (1972). An associative basis for coding and organization in memory. In A. W. Melton \& E. Martin (Eds.), Coding processes in human memory (pp. 161-190). Washington, DC: Winston.

Glenberg, A. M., Bradley, M. M., Kraus, T. A., \& Renzaglia, G. J. (1983). Studies of the long-term recency effect: Support for a contextually guided retrieval hypothesis. Journal of Experimental Psychology: Learning, Memory, \& Cognition, 9, 231-255.

Glenberg, A. M., \& Swanson, N. (1986). A temporal distinctiveness theory of recency and modality effects. Journal of Experimental Psychology: Learning, Memory, \& Cognition, 12, 3-24.

GoschKe, T., \& KuHL, J. (1993). Representation of intentions: Persisting activation in memory. Journal of Experimental Psychology: Learning, Memory, \& Cognition, 19, 1211-1226.
Goschke, T., \& KuhL, J. (1996). Remembering what to do: Explicit and implicit memory for intentions. In M. Brandimonte, G. O. Einstein, \& M. A. McDaniel (Eds.), Prospective memory: Theory and applications (pp. 53-91). Mahwah, NJ: Erlbaum.

Herrmann, D. J., \& Murray, D. J. (1979). The role of category size in continuous recall from semantic memory. Journal of General Psychology, 101, 205-218.

MandelBrot, B. B. (1997). Fractals and scaling in finance. New York: Springer-Verlag.

Mandelbrot,B. B., \& Wallis, J. R. (1969). Some long-run properties of geophysical records. Water Resources Research, 5, 321-340.

MarSh, R. L., Hicks, J. L., \& Bink, M. L. (1998). The activation of completed, uncompleted, and partially completed intentions. Journal of Experimental Psychology: Learning, Memory, \& Cognition, 24, 350-361.

Marsh, R. L., Hicks, J. L., \& Bryan, E. S. (1999). The activation of unrelated and canceled intentions. Memory \& Cognition, 27, 320-327.

McCrary, J. W., \& Hunter, W. S. (1953). Serial position curves in verbal learning. Science, 117, 131-134.

NAIRne, J. S. (1991). Positional uncertainty in long-term memory. Memory \& Cognition, 19, 332-340.

Nairne, J. S., Neath, I., Serra, M., \& Byun, E. (1997). Positional distinctiveness and the ratio rule in free recall. Journal of Memory \& Language, 37, 155-166.

Wixted, J. T., \& EBbesen, E. B. (1991). On the form of forgetting. Psychological Science, 2, 409-415.

Wixted, J. T., \& Rohrer, D. (1994). Analyzing the dynamics of free recall: An integrative review of the empirical literature. Psychonomic Bulletin \& Review, 1, 89-106.

Voss, R. F. (1978). 1/f noise in music; music from 1/f noise. Journal of the Acoustical Society of America, 63, 258-263.

Voss, R. F., \& Clark, J. (1975). "1/f noise" in music and speech. Nature, 258, 317-318.

(Manuscript received July 28, 1999; revision accepted for publication March 1, 2000.) 